\title{
STENTING PADA SINUS VENOSUS SEREBRAL DENGAN HIPERTENSI INTRAKRANIAL IDIOPATIK
}

\author{
CEREBRAL SINUS VENOSUS STENTING IN IDIOPATHIC INTRACRANIAL \\ HYPERTENSION
}

Fritz Sumantri Usman, * Gamaliel Wibowo Soetanto, ** Pinto Desti Piliang, ** Audhy Tanasal, ** Hernawan, ** Trenggono Yudo, ** Ahmad Sulaiman Alwahdy**

\begin{abstract}
Idiopathic intracranial hypertension (IIH) is a group of symptoms caused by increase in intracranial pressure without any damage of brain parenchyma. Idiopathic intracranial hypertension is usually known as cerebral pseudotumor. This disease can cause visual disturbance, even visual loss, thus decrease quality of daily living. Treatment of this disease consists of disease modifying, medicine, surgery and neurovascular interventional procedure such as venous sinus stenting. High risk in failure and complication of surgery gives venous sinus stent procedure a chance to grow. Case reports and meta-analysis showed that venous sinus stent has high success rate and very low complication rate.
\end{abstract}

Keywords: Cerebral pseudotumor, intracranial idiopathic hypertension (IIH), venous sinus stent (VSS)

\section{ABSTRAK}

Hipertensi intrakranial idiopatik (HII) merupakan kumpulan gejala akibat peningkatan tekanan intrakranial tanpa dijumpai adanya kelainan pada parenkim otak. HII sering dikenal dengan pseudotumor serebri. Penyakit ini dapat menimbulkan penurunan kualitas hidup sehari-hari dengan timbulnya penurunan tajam penglihatan bahkan memiliki potensi kebutaan. Tata laksana HII terdiri dari medikamentosa, operatif dan prosedur neurovaskular intervensi berupa prosedur stent sinus venosus. Risiko kegagalan dan angka komplikasi yang tinggi pada tindakan operatif memberikan kesempatan pada prosedur stent sinus venosus untuk berkembang. Laporan kasus, penelitian dan uji meta analisa memberikan kesimpulan bahwa prosedur stent sinus venosus memberikan angka keberhasilan yang tinggi dan angka komplikasi yang sangat rendah.

Kata kunci: Hipertensi intrakranial idiopatik (HII), pseudotumor serebri, stent sinus venosus

*KSM Neurologi RSUP Fatmawati, Jakarta; **Diklat Neurointervensi RSUP Fatmawati, Jakarta. Korespondensi: fritz.sumantri@ gmail.com.

\section{PENDAHULUAN}

Hipertensi Intrakranial Idiopatik (HII) adalah kelainan dimana ditemukan adanya peningkatan tekanan didalam rongga otak tanpa disertai kelainan pada parenkim otak. HII biasanya ditemukan pada perempuan dengan obesitas dalam rentang usia subur. Gejala yang ditemukan berupa tinitus pulsatil, yaitu tinitus yang sinkron dengan denyut nadi, diplopia akibat kelumpuhan saraf kranial keenam, dan penurunan tajam penglihatan akibat edema papil. ${ }^{1-2}$ Pendekatan terapeutik dengan menurunkan berat badan, penggunaan medikamentosa (asetazolamid dan topiramat) serta pembedahan telah banyak dilakukan. Prosedur operasi yang sering dilakukan, yaitu optic nerve sheath fenestration (ONSF) dan shunt cairan serebrospinal. Khususnya pada prosedur shunt, sering dilaporkan tingginya angka kegagalan dan komplikasi. Pendekatan neurovaskular intervensi mulai diterima sejak tahun 2002. Laporan kasus, penelitian dan metaanalisis telah banyak dilakukan pada stent sinus venosus untuk tata laksana HII.
Prosedur stenting pada sinus venosus serebral ternyata memberikan hasil yang baik. ${ }^{3}$ Artikel ini akan membahas pendekatan tata laksana neurovaskular intervensi dengan prosedur stenting sinus venosus serebral pada kasus hipertensi intrakranial idiopatik.

\section{PEMBAHASAN}

\section{Penggunaan Istilah Hipertensi Intrakranial Idiopatik, Benign Intracranial Hypertension dan Sindrom Pseudotumor}

Seringkali penegakan diagnosis HII mengalami kesulitan terutama bila tidak ditemukan adanya edema papil atau pada pasien anak dimana tekanan cairan serebrospinal (CSS) dalam batas normal. Faktor-faktor presipitasi terkait dengan terjadinya HII memberikan keraguan diagnosis HII yang seharusnya bersifat idiopatik. Oleh karena itu, dibutuhkan kriteria yang dapat digunakan untuk menyelesaikan masalah-masalah ini. Secara umum, HII sering disebut dengan istilah pseudotumor serebri. Namun, hipertensi intrakranial ringan sebaiknya tidak dipakai 
karena kelainan ini memiliki potensi mengakibatkan penurunan kualitas hidup akibat hilangnya fungsi penglihatan. ${ }^{1}$

Sindrom pseudotumor serebri dibagidalam dalam kategori pseudotumor serebri primer dan pseudotumor serebri sekunder. HII tergolong kedalam pseudotumor serebri primer (Tabel 1). diagnostik pseudotumor/HII pada saat itu, namun temuan kasus yang dicurigai pseudotumor serebri dengan adanya tekanan pembukaan $\mathrm{CSS}>200 \mathrm{mmHg}$ tetapi disertai dengan nyeri kepala dan tinitus. ${ }^{2}$

Friedman dkk, mengusulkan kriteria diagnostik HII yang pada saat ini dipakai dalam penelitianpenelitian HII (Tabel 2). ${ }^{2}$

Tabel 1. Sindrom Pseudotumor Serebri²

No Klasifikasi

1. Pseudotumor Serebri Primer

Hipertensi Intrakranial Idiopatik

(Pasien dengan obesitas, kenaikan berat badan dalam waktu dekat, sindrom polikistik ovarium dan anak bertubuh kurus)

2. Pseudotumor Serebri Sekunder

a. Anomali Venosus Serebral

Trombosis Sinus Venosus

Trombosis Vena Jugular Bilateral atau operasi ligasi

Mastoiditis atau infeksi telinga tengah

Peningkatan tekanan jantung kanan

Sindrom Vena Kava Superior

Fistula Arteriovenous

Penurunan absorpsi akibat dari infeksi intrakranial sebelumnya atau akibat

Perdarahan Subaraknoid

Kondisi Hiperkoaguabilitas

b. Medikasi atau Paparan

Antibiotik (Tetrasiklin, minosiklin, doksisiklin, nalidixic acid, sulfa)

Vitamin A (Hipervitamin A, isotretinoin, trans retinoic acid untuk promyelocytic leukemia, asupan liver berlebih)

Hormon (Human growth hormone, tiroksin (pada pasien anak), leuprorelin acetate, levonorgestrel, steroid anabolik)

Efek withdrawal dari penggunaan steroid jangka panjang

Litium

Chlordecone

c. Kondisi Medis

Gangguan Endokrin (Addison, hiperparatiroid)

Hiperkapnia (sleep apnea, sindrom pickwickian)

Anemia

Gagal ginjal

Sindrom Turner

Sindrom Down

Laporan Dandy pada tahun 1930 selama ini dipakai menjadi dasar diagnosis HII, dimana saat itu alat diagnostik untuk menegakan HII yang tersedia sangat terbatas yaitu berupa pneumoensefalografi (trephine dan injeksi udara) dan punksi lumbal. Sehingga, mungkin saja tidak semua kasus yang dilaporkan adalah HII tetapi memiliki kemiripan gejala, seperti pada kasus: pleositosis CSS, trauma kepala, drowsiness dan hemiplegia yang transien. Sebenarnya Dandy tidak mengusulkan kriteria

\section{Patofisiologi Hipertensi Intrakranial Idiopatik}

Insiden hipertensi intrakranial idiopatik ditemukan pada sekitar 12-20 per-100.000 wanita dengan obesitas pada usia subur pertahun namun hanya ditemukan sebesar $0,5-2$ per-100.000 pada populasi umum. Belum diketahui insiden HII di Indonesia. Patofisiologi HII belum dapat diketahui secara pasti dan belum ada satupun teori yang cukup kuat untuk menjelaskan penyakit ini. Sistem saraf pusat dialiri oleh sekitar $140 \mathrm{~mL}$ CSS 


\section{Tabel 2. Hipertensi Intrakranial Idiopatik berdasarkan Kriteria Dandy dengan Modifikasi²}

No Kriteria

1. Keluhan dan gejala peningkatan tekanan intrakranial

2. Tidak ditemukan gejala neurologis fokal

3. Tidak ditemukannya deformitas, displacement, obstruksi sistem ventrikel atau pemeriksaan normal pada neurodiagnostik kecuali peningkatan tekanan cairan serebrospinal $>200 \mathrm{mmH}_{2} \mathrm{O}$, hasil pemeriksaan radiologis normal kecuali ditemukannya sella turcica yang kosong, pembungkus nervus optikus terisi ruangan cairan serebrospinal dan ditemukannya stenosis atau kolaps sinus venosus yang terkait dengan diagnosis lainnya.

4. Sadar

5. Tidak ditemukan penyebab peningkatan tekanan intrakranial lain

Bila ditemukan tekanan pembukaan cairan serebrospinal $200-250 \mathrm{mmH}_{2} \mathrm{O}$ diperlukan setidaknya salah satu tanda dibawah ini:

a. Tinitus yang sinkron dengan denyut nadi

b. Kelumpuhan saraf kranialis VI

c. Edema papil grade II berdasarkan Frisen

d. Pemeriksaan echography negatif untuk penyakit drusen dan kelainan lain yang mengakibatkan edema pada diskus

e. Ditemukan kolaps atau stenosis sinus lateral pada pemeriksaan Magnetic Resonance Venography

f. Tampak sella yang kosong pada potongan koronal atau sagital dengan nervus optikus terisi oleh ruangan serebro spinal pada pemeriksaan potongan aksial pada gambaran $\mathrm{T} 2$

dan mengalami sirkulasi 3-4 kali perhari. Cairan serebrospinal disekresi oleh pleksus koroid. Tiga mekanisme telah diusulkan terkait gangguan aliran CSS yaitu: peningkatan sekresi, gangguan absorpsi dan peningkatan tekanan sinus venosus (Gambar 1$){ }^{3}$ sering ditemukan adalah pada sinus transversus (Gambar 2). Walaupun demikian derajat stenosis tidak berkaitan dengan luaran klinis dan tekanan pembukaan CSS. Prosedur untuk mengalihkan dan memindahkan CSS mengakibatkan penurunan

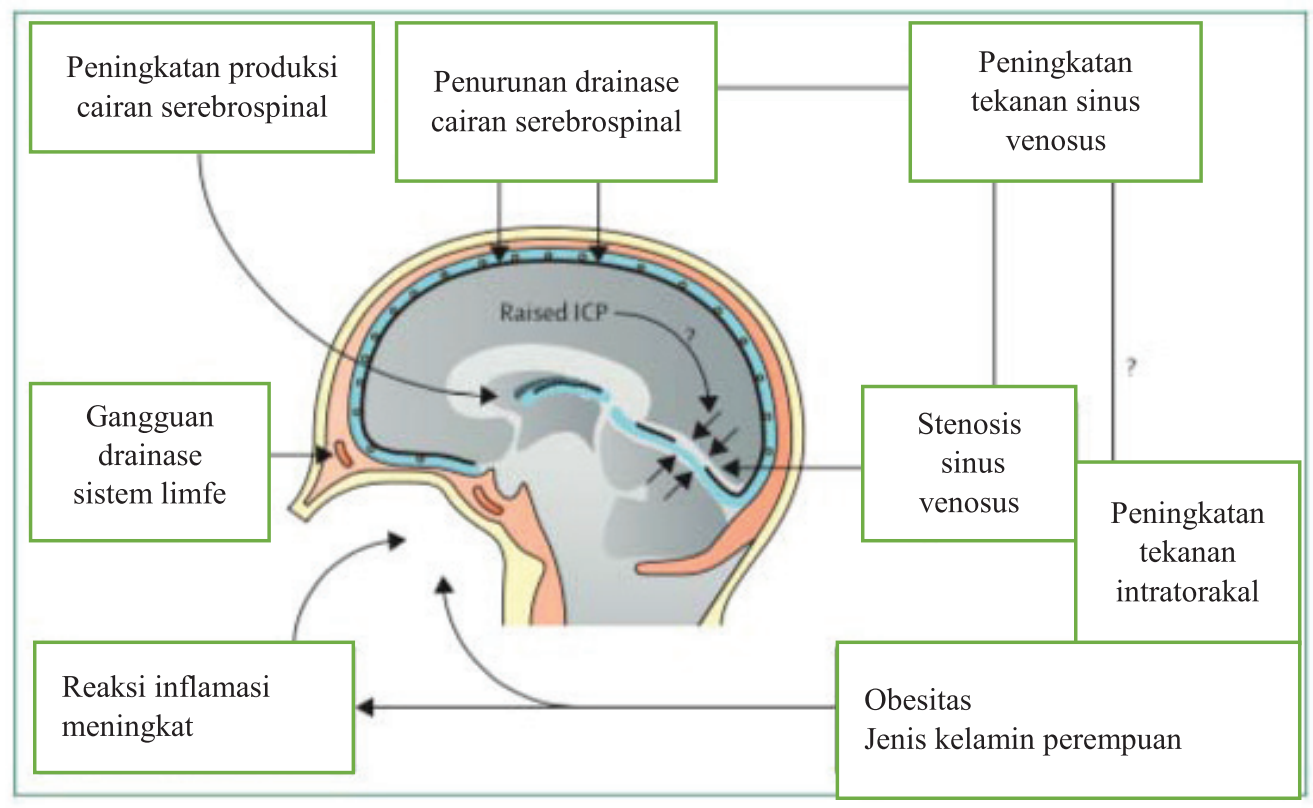

Gambar 1. Mekanisme Terjadinya Hipertensi Intrakranial Idiopatik ${ }^{3}$

Peningkatan tekanan sinus venosus akibat dari stenosis sinus venosus dianggap sebagai mekanisme yang paling dapat diterima dan sering ditemukan pada HII. Stenosis sinus venosus yang paling tekanan intrakranial. Penurunan tekanan intrakranial ternyata dapat memulihkan stenosis sinus venosus. Hal ini memberikan asumsi bahwa stenosis sinus venosus merupakan akibat dari HII, bukan etiologi 
sehingga tetap menjadi kontroversi apakah stenosis sinus venosus adalah etiologi atau konsekuensi. ${ }^{4}$

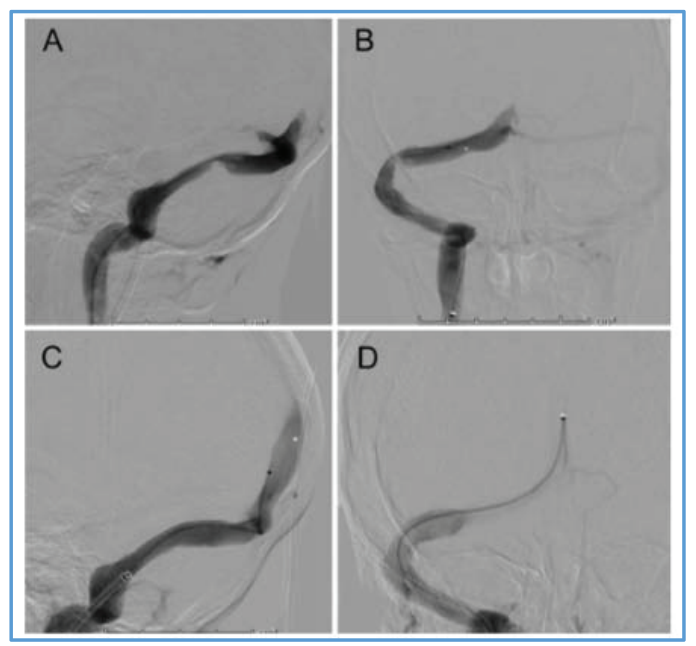

Gambar 2. Stenosis pada Sinus Transversus Kanan

A. Gambar potongan lateral, B. Gambar potogan koronal, memperlihatkan adanya stenosis pada sinus transversus kanan sebelum pemasangan stent. C. Gambar potongan lateral dan D. potongan koronal setelah pemasangan stent. ${ }^{15}$

\section{Tata Laksana Teknik Modifikasi Penyakit dan Medikamentosa}

Penurunan berat badan memegang peranan penting dalam tata laksana HII. Menurunkan berat badan dapat memperbaiki edema papil dan gejala HII. ${ }^{5}$ Kesimpulan ini diperoleh dari penelitian dengan metode kohort yang dilakukan pada 25 pasien perempuan penderita HII. Pasien-pasien ini diberikan diet 425 kalori perhari selama 3 bulan. Pasien mengalami penurunan berat badan sebesar $15 \%$ dan penurunan tekanan intrakranial, nyeri kepala dan edema papil. ${ }^{6}$

Asetazolamid sering digunakan dalam tata laksana HII karena mampu mengurangi sekresi CSS di pleksus koroideus. Obat ini mampu menghambat enzim karbonat anhidrase yang merupakan katalisator perubahan air dan karbondioksida menjadi bikarbonat dan ion hidrogen sehingga mengganggu transport ion. Akibat proses ini adalah penurunan pergerakan ion dan air melewati pleksus koroid sehingga mengurangi sekresi CSS. Wall dkk, pada tahun 2014 melaporkan efektivitas asetazolamid pada pasien HII dibandingkan dengan plasebo. Grup asetazolamid mengalami perbaikan dalam edema papil, namun tidak ada perbaikan tajam penglihatan. Nyeri kepala dilaporkan mengalami perbaikan pada grup plasebo dan asetazolamid. ${ }^{7}$

Topiramat memiliki efek inhibisi terhadap enzim karbonat anhidrase ringan, efek profilaksis terhadap migrain dan memiliki efek samping berupa penurunan nafsu makan. Pada penelitian yang membandingkan topiramat (100-150mg per hari) dengan asetazolamid (1000-1500mg per hari) pada penelitian open label terhadap 40 pasien, memberikan hasil adanya perbaikan pada kedua grup, tanpa adanya perbedaan yang bermakna. ${ }^{8}$

\section{Tata Laksana Operatif}

Optic nerve sheath fenestration (ONSF) merupakan prosedur yang bermanfaat untuk mengurangi papil edema terkait kehilangan penglihatan pada kasus HII. ${ }^{9}$ Mekanisme prosedur ini tidak menurunkan tekanan intrakranial namun menurunkan tekanan CSS pada retrolaminar nervus optikus. Tindakan operasi ini sangat disarankan pada pasien HII yang mengalami penurunan visus yang progresif tanpa keluhan nyeri kepala. Komplikasi prosedur ini adalah: oklusi pembuluh darah retina, infeksi pascaoperatif, diplopia, perdarahan orbita dan anisokor. Bila perburukan tajam penglihatan tetap terjadi maka prosedur pembedahan yang lain perlu dilakukan segera. ${ }^{10}$

Operasi pemasangan piraiventrikuloperitoneal atau lumboperitoneal merupakan prosedur pilihan dalam HII, bila tata laksana medikamentosa telah dinyatakan gagal. ${ }^{9}$ McGirt $\mathrm{dkk}$, melaporkan hasil penelitian pada 42 pasien HII yang telah dilakukan prosedur operasi pemasangan pirai, sebanyak $95 \%$ mengalami perbaikan nyeri kepala, walaupun $86 \%$ prosedur mengalami kegagalan. ${ }^{11}$ El-Saadany dkk, melaporkan adanya perbaikan terhadap keluhan nyeri kepala sebesar $86 \%$ dan perbaikan pada edema papil sebesar $82 \%$ pada 22 pasien yang dilakukan operasi pemasangan pirai lumboperitoneal. ${ }^{12}$ Dalam penelitian ini juga dilaporkan $9 \%$ infeksi pada alat pirai, $27 \%$ obstruksi saluran pirai, dan $13 \%$ risiko drainase berlebihan. Tamaris dkk, melaporkan terjadinya komplikasi sebesar $20,5 \%$ pada 34 pasien yang menjalani 63 prosedur operasi pemasangan 
pirai. Operasi pemasangan pirai lumboperitoneal memiliki angka komplikasi intrakranial yang lebih rendah namun berpotensi menyebabkan komplikasi lain berupa: infeksi alat pirai, hematoma subdural, penurunan tonsil serebelum dan migrasi kateter bagian distal sehingga diperlukan operasi ulang untuk memperbaiki posisi kateter. ${ }^{13}$

\section{Tata Laksana Neurovaskular Intervensi}

Stenting sinus venosus serebral untuk tata laksana HII berlandaskan pada sering ditemukannya obstruksi aliran keluar sinus venosus. Bahkan temuan ini dianggap sebagai salah satu kemungkinan terjadinya HII. ${ }^{14}$ Kateter $6 \mathrm{Fr}$ digunakan untuk mengantarkan ke sistem vena dengan 0,035 inci Glidewire (Terumo International). Semua sistem ini masuk kedalam vena kava inferior menuju vena kava superior lalu kedalam vena jugularis komunis kanan atau vena jugularis kanan tergantung pada dominansi sinus. Sampai kepada bulbus jugularis, kateter 3-4Fr masuk kedalam kateter $6 \mathrm{Fr}$ untuk masuk kedalam sinus sagitalis anterior (Gambar 3). Venogram sinus sagitalis anterior dilakukan untuk mengevaluasi seluruh sistem drainase vena. Sinus sigmoid kontralateral dan sinus transversus juga dikanulasi dengan menggunakan kateter 3-4Fr. Setelah venografi dilakukan, tekanan sinus diukur dan dibandingkan antara dua lokasi. Gambaran fluoroskopi diambil pada setiap tempat dimana pengukuran tekanan dilakukan. Perbedaan tekanan adalah kunci untuk menemukan lokasi obstruksi. Pengukuran dilakukan dari bulbus jugularis ke sinus sigmoid menuju sinus transversus. Kemudian diulangi dari torcula melewati sistem sinus venosus ipsilateral. Setelah lokasi obstruksi ditemukan, 0,018inci guidewire digunakan untuk menghantarkan stent 8x60 inci. Pada akhir prosedur pengukuran tekanan dilakukan kembali untuk memastikan penurunan tekanan. ${ }^{15}$

Dinkin melaporkan prosedur pemasangan stent berukuran diameter $8-10 \mathrm{~mm}$ dengan panjang 30$40 \mathrm{~mm}$ segera setelah dilakukan venogram diagnostik pada 12 dari 13 pasien HII. Prosedur ini dilakukan tanpa melakukan pengukuran tekanan pada sinus transversus tersebut. Sebelum prosedur dilakukan setiap pasien diberikan klopidogrel $75 \mathrm{mg}$ dan aspirin

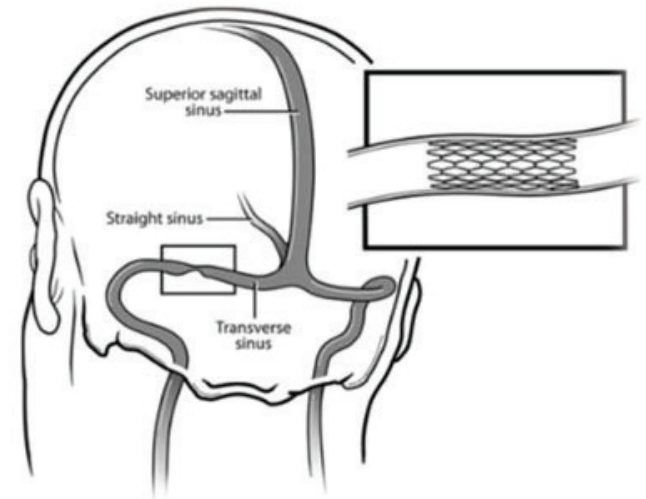

Gambar 3. Ilustrasi Sinus Transversus Kanan setelah Pemasangan Stent ${ }^{15}$

$325 \mathrm{mg}$ selama minimal 2 hari. Pemberian klopidogrel selama 1 bulan setelah prosedur dan aspirin tetap diberikan selama 6 bulan. Sebanyak 11 pasien yang mengalami tinitus, mengalami resolusi seluruhnya. Keluhan nyeri kepala mengalami perbaikan pada $84,7 \%$ dan gangguan visus mengalami perbaikan pada $100 \%{ }^{16}$

Evaluasi manfaat prosedur stenting ini seringkali hanya dilakukan melalui pemeriksaan fungsi visual, namun Smith KA dkk, melaporkan evaluasi dengan menggunakan optical coherence tomography (OCT). Optical coherence tomography merupakan pemeriksaan non invasif menggunakan spektroskopi infra merah jarak pendek untuk menilai ketebalan peripapillaryretinal nerve fiber layer (RNFL) yang merupakan pemeriksaan untuk menilai edema papil secara objektif. Sebanyak 14 (82\%) dari 17 pasien yang mengikuti penelitian ini mengalami perbaikan penglihatan. Penilaian dengan OCT memperlihatkan perbaikan pada sebesar $72,7 \%$ dari seluruh pasien. Komplikasi prosedur tidak ditemukan pada seluruh pasien yang diikuti selama 1 tahun. ${ }^{17}$

Boddu S dkk, melaporkan resolusi tinitus pulsatil pada 29 pasien yang dilakukan stenting sinus venosus. Tinitus hilang atau berkurang pada hari yang sama setelah prosedur kecuali 3 pasien (10\%) yang mengalami stenosis sinus rekuren. Hilangnya tinitus mungkin terkait dengan mekanisme munculnya tinitus yang dicurigai akibat aliran turbulensi pada lokasi stenosis yang mengalir ke koklea melalui konduksi tulang. ${ }^{18}$ Manfaat stent sinus venosus 
terhadap penurunan tekanan intrakranial baru-baru ini dilaporkan oleh Patsalides dkk. Tekanan intrakranial rata-rata berkurang sebesar $45 \%$ secara bermakna pada 50 pasien yang ikut serta dalam penelitian ini. Tekanan intrakranial diukur dengan lumbal pungsi yang dituntun dengan fluoroskopi tiga bulan sebelum dan 3 bulan setelah prosedur. ${ }^{19}$

Saber dkk, melakukan metaanalisis pada sebanyak 24 penelitian yang mencakup 473 pasien yang dilakukan prosedur stenting sinus venosus serebral untuk tata laksana HII. Perbaikan 77\% terhadap nyeri kepala (256/330), 85,8\% perbaikan pada edema papil (247/288), 70.3\% perbaikan tajam penglihatan (121/172) dan 84,5\% perbaikan pada tinitus (93/110). Fungsi stent bertahan pada $84 \%$ dari seluruh prosedur selama observasi selama 20 bulan. Revisi stent kadang diperlukan karena adanya stenosis pada proksimal atau distal dari stent. ${ }^{20}$

Nicholson dkk juga melakukan metaanalisis terhadap 22 penelitian sehingga didapatkan sebanyak 474 pasien HII yang menjalani prosedur stenting sinus venosus serebral. Pasien diobservasi sepanjang 18 bulan dan diperoleh hasil perbaikan edema papil sebesar 93,7\%, perbaikan nyeri kepala sebesar $79,6 \%$, perbaikan tinitus sebesar 90,3\%. Rekurensi HII setelah menjalani prosedur stenting sinus venosus serebral adalah sebesar 9,8\%. Komplikasi berupa hematoma subdural dan perdarahan subaraknoid ditemukan kurang dari $1 \% .{ }^{21}$

\section{KESIMPULAN}

Sebagian besar pasien yang telah didiagnosis dengan HII, pada banyak laporan kasus telah ditemukan adanya kolaps atau stenosis pada sinus venous serebral, tetapi tidak ditemukan gejala penyakit lain selain gejala HII. Atas dasar hal tersebut, klinisi perlu mempertimbangkan pemeriksaan angiografi vena serebral pada pasien pasien dengan HII. Pada temuan adanya kolaps atau stenosis pada sinus vena serebral pada angiografi pasien dengan HII, prosedur stenting sinus venosus serebral yang merupakan tata laksana dengan pendekatan neurovaskular intervensi perlu dipertimbangkan mengingat keberhasilan dan angka rekurensi serta komplikasi pascaprosedur yang kecil.

\section{DAFTAR PUSTAKA}

1. Friedman DI, Liu GT, Digre KB. Revised diagnostic criteria for the pseudotumor cerebri syndrome in adults and children. Neurology. 2013;81:1159-65.

2. Friedman DI, Liu GT, Digre KB. Revised diagnostic criteria for the pseudotumor cerebri syndrome in adults and children. Neurology. 2013;83:198-200.

3. Markey KA, Mollan SP, Jensen RH, Sinclair AJ. Understanding idiopathic hypertension: Mechanism, management, and future direction. Lancet Neurol. 2016;15:78-91.

4. Matloob SA, Toma AK, Thompson SD, Gan CL, Robertson F, Thorne L, dkk. Effect of venous stenting on intracranial pressure in idiopathic intracranial hypertension. Acta Neurochir. 2017;159(8):1429-37.

5. Subramaniam S, Fletcher WA. Obesity and weight loss in idiopathic intracranial hypertension: A narrative review. J Neuroopthalmol. 2017;37(2):197205.

6. Piper RJ, Kalyvas AV, Young AM, Hughes MA, Jamjoom AA, Fouyas IP. Intervention for idiopathic hypertension (review). Cochrane Database of Systematic Reviews. 2015;8: CD003434.

7. Wall M, McDermott MP, Kieburtz KD, dkk for the NORDIC Idiopathic Intracranial Hypertension Study Group Writing Committee. Effect of asetazolamid on visual function in patients with idiopathic intracranial hypertension and mild visual loss: The idiopathic intracranial hypertension treatment trial. JAMA. 2014;311:1641-51.

8. Celebisoy N, Gokcay F, Sirin H, Akyurekli O. Treatment of idiopathic intracranial hypertension: Topiramate vs asetazolamid, an open-label study. Acta Neurol Scand. 2007;116:322-27.

9. Spitze A, Malik A, Lee AG. Surgical and endovascular interventions in idiopathic intracranial hypertension. Curr Opin Neurol. 2014;27: 69-74.

10. Wakerley BR, Tan MH, Ting EY. Idiopathic intracranial hypertension. Cephalgia. 2015;35(3):24861.

11. Hermann EJ, Polemikos M, Heissler HE, Krauss JK. Shunt surgery in idiopathic intracranial hypertension aided by electromagnetic navigation. Stereotact Funct Neurosurg. 2017;95:26-33.

12. Karsy M, Abou-Al-Shaar H, Bowers C, Schmidt RH. Treatment of idiopathic intracranial hypertension via stereotactic placement of biventriculoperitoneal shunts. J Neurosurg. 2018; 1(aop):1-9.

13. Alkosha HM, Zidan AS. Role of lumbopleural shunt in management of idiopathic intracranial hypertension. World Neurosurgery. 2016;88:113-8.

14. Biousse V, Bruce BB, Newman NJ. Update on the 
pathophysiology and management of idiopathic intracranial hypertension. J Neurol Neurosurg Psychiatry. 2012;83:488-94.

15. Cappuzzo JM, Hess RM, Morrison JF, Davies JM, Snyder KV, Levy EI, dkk. Transverse venous stenting for the treatment of idiopathic intracranial hypertension, or pseudotumor cerebri. Neurosurg Focus.2018;45(1):E11.

16. Smith KA, Peterson JC, Arnold PM, Camarata PJ, Whittaker TJ, Abraham MG. A case series of dural venous sinus stenting in idiopathic intracranial hypertension: Association of outcomes with optical coherence tomography. Int $\mathrm{J}$ Neurosci. 2017;127(2):145-53.

17. Dinkin MJ, Patsalides A. Venous sinus stenting in idiopathic intracranial hypertension: Result of a prospective trial. Journal of Neuro-opthalmology. 2017;37(2):113-21.

18. Boddu S, Dinkin M, Suurna M, Hannsgen K, Bui $\mathrm{X}$, Patsalides A. Resolution of pulsatile tinnitus after venous sinus stenting in patients with idiopathic intracranial hypertension. PLoS One. 2016;11(10):e0164466.

19. Patsalides A, Oliveira C, Wilcox J, Brown K, Grover $\mathrm{K}$, Gobin YP, dkk. Venous sinus stenting lowers the intracranial pressure in patients with idiopathic intracranial hypertension. J Neurointervent Surg. 2019;11;175-8.

20. Saber H, Lewis W, Sadeghi M, Rajah G, Narayanan S.Stent survival and stent-adjacent stenosis rates following venous sinus stenting for idiopathic intracranial hypertension: A systematic review and meta-analysis. Intervent Neurol. 2018;7(6):490-500.

21. Nicholson P, Brinjikji W, Radovanovic I, Hilditch CA, Tsang AC, Krings $\mathrm{T}$, dkk. Venous sinus stenting for idiopathic intracranial hypertension: A systematic review and metanalysis. J NeuroIntervent Surg.2019;11(4):380-5. 